24 of the patients had arthralgia and arthritis, 22 swelling of the hands and fingers, many with skin changes of scleroderma, 21 Raynaud's disease, 18 myositis, 17 lymphadenopathy, and 20 hypergammaglobulinaemia. Several had skin rashes typical of dermatomyositis, and of the 22 patients on whom cine-oesophograms were performed 17 showed abnormal motility such as found in scleroderma. Histopathology entirely confirmed these clinical findings. Thus six out of 10 skin biopsies were characteristic of scleroderma and seven out of eight muscle biopsies showed inflammatory infiltrates, so confirming the presence of myositis already indicated by typical electromyograms and raised levels of creatine phosphokinase. Only four patients had an erythematous rash similar to that of systemic lupus, and, of especial significance, only one patient developed a renal lesion of indeterminate nature despite the length of followup, which ranged from 8 weeks to 8 years.

In support of the hypothesis that mixed connective tissue disease is an entity distinct from the hitherto recognized diseases of the connective tissues is the presence in all 25 patients of an antibody to an extractable nuclear antigen, which in its purest form so far obtained is an RNA protein of molecular weight greater than 20,000 . The specific antibody is readily detected by tanned cell agglutination, and in these patients it was detected at dilutions between 1 in 1,000 and 1 in $1,000,000$. The only other conditions in which a similar antibody was found was systemic lupus erythematosus, but that antibody could be readily distinguished from the one in mixed connective tissue disease because of its much lower titre and because the agglutination of the coated cells was resistant to the action of RNAse.

The response of these patients to high doses of prednisone, $1 \mathrm{mg} / \mathrm{kg}$ body weight daily, was usually good, and the majority required little or no maintenance therapy. Even the sclerodermatous changes, in contrast to classical scleroderma, responded in a satisfactory manner.

Should mixed connective tissue disease be regarded as distinct from the other recognized diseases of the connective tissues? Since it can be differentiated from them on both clinical and serological grounds, and since it carries a more benign prognosis, with clear-cut therapeutic requirements, the differentiation would appear to worth making.

1 Dubois, E. L., Chandor, S., Friou, G. J., and Bishel, M., Medicine, 1971, 50, 199.

2 D'Angelo, W. A., Fries, J. F., Masi, A. T., and Shulman, L. E., American Fournal of Medicine, 1969, 46, 428.

Tuffanelli, D. L., and Winkelmann, R. K., Archives of Dermatology, 1961, 84, 359 .

- Sharp, G. C., Irvin, W. S., Tan, E. M., Gould, R. G., and Holman, H. R., American Fournal of Medicine, 1972, 52, 148.

\section{Renal Radiology}

Recent advances in the treatment of renal disease have been accompanied by equally impressive progress in the histopathology, immunology, bacteriology, and physiology of the kidney. Radiology has not lagged behind. Originally the intravenous pyelogram, as its name implies, was used mainly to examine the kidney's drainage system, but now as much attention is paid to the nephrogram, and it would be more correct to refer to it as an intravenous urogram. Furthermore, radiology no longer provides only a static picture of renal structure; it has become an important tool in the dynamic study of functional disturbance in disease. The current edition of the British Medical Bulletin, which is devoted to renal radiology, provides a timely review of the clinical status and potential for research in the field.

Undoubtedly the most important practical innovation has been the recognition that the use of high dosage of the contrast media enables a useful urogram to be obtained in patients with severe renal failure. Since obstruction of the urinary tract can often be excluded by this means, the need for the more difficult and hazardous retrograde pyelography has been lessened. The excretory urogram is of value even in the differential diagnosis of oliguric acute renal failure. For example, acute tubular necrosis characteristically produces an immediate, dense, and persistent nephrogram with little or no pyelogram, an appearance which has been observed in only one other condition-acute suppurative pyelonephritis. In addition this observation has helped our understanding of the pathogenesis of acute tubular necrosis, since it supports the theory of continuing glomerular filtration with almost complete reabsorption of tubular fluid. I. K. Fry and W. R. Cattell have been pioneers in the dynamic interpretation of the excretory urogram, and in the British Medical Bulletin they analyse in detail the nephrographic pattern in various disorders. The safety of the contrast media is fundamental to their use in high dosage, and from a comprehensive account of their toxicity by R. G. Grainger it is reassuring to learn that with simple precautions, especially against dehydration, the present-day agents are remarkably safe.

Arteriography is a well-established technique for the investigation of the major renal vessels and of renal tumours and cysts, but little attention has been paid to the smaller vessels. Macro-angiography, however, enables vessels as small as the interlobular arteries to be visualized, and M. E. Sidaway describes characteristic patterns in diseases such as hypertension, chronic pyelonephritis, and polyarteritis nodosa. J. P. Lavender and T. Sherwood give other examples of the use of radiology in pathophysiological research with their studies of the renal microcirculation in experimental haemorrhagic hypertension in the dog. Bone disease in uraemia, formerly little more than a pathological curiosity, has increased in importance with the advent of long-term haemodialysis, for it has crippled many otherwise rehabilitated patients. Separation of the various radiological patterns is necessary for the rational choice of treatment, and these are detailed, together with a correlation with bone histology, by F. H. Doyle and his colleagues.

Other articles deal with the techniques of videocystography, topographical scintigraphy, and ultrasonic and isotopic diagnostic methods. Any clinician or radiologist with a special interest in renal diseases will find this issue of the Bulletin a useful progress report in a rapidly advancing field.

1 British Medical Bulletin, 1972, 28, No.3.

\section{Pertussis in Adults}

If a doctor has spent a large part of his life working in the whooping-cough wards of an infectious diseases hospital, he will probably have seen a few cases of whooping-cough in adults. No doctor will have seen many, for whooping-cough is a disease of early childhood. But no age group is immune..$^{1-3}$ Second attacks may occur, though very rarely. ${ }^{34}$ And immunization does not confer life-long immunity. 5

An attack in the adult may be typical or atypical. In the 